\title{
MEASUREMENT OF POWER LINE FLICKER INDUCED BY THE AGS BOOSTER
}

\section{BOOSTER TECHNICAL NOTE \\ NO. 215}

M. METH, J. BENSON, A.J. McNERNEY

December 14, 1992

\section{ALTERNATING GRADIENT SYNCHROTRON DEPARTMENT \\ BROOKHAVEN NATIONAL LABORATORY \\ UPTON, NEW YORK 11973}




\section{MEASUREMENT OF POWER LINE FLICKER INDUCED BY THE AGS BOOSTER}

\section{Introduction}

This report summarizes a series of coordinated measurements to determine the impact of the AGS Booster magnet power supplies on the $60 \mathrm{hz}$ power grid. The AC power requirements of these supplies is characterized as a pulsed-power load, generating amplitude and phase flicker both at the lab site and on the LILCO grid. To minimize the impact of the pulsed power on the power grid, the Booster magnet power supplies are fed from a dedicated $69 \mathrm{Kv}$ line LILCO 69-861, termed the alternate feed, and a dedicated 20 MVA transformer. This is transformer \#7, which is installed at the Fifth Avenue substation.

During the recent run (June-July 1992) of the AGS Booster, measurements were obtained for the AC power, both real and reactive, and the induced power line flicker. The flicker measurements are compared to projected values of flicker. During the development phase of the Booster, the proton-cycle energy and repetition rate varied resulting in a spread of projected flicker values. Measurements obtained during this run are compared to the values calculated in Booster Tech. Note 45, "Calculation of Booster Power Requirements Based on a Constant RF Bucket Area". For both situations the calculated peak power swing is approximately $17 \mathrm{MW}$.

During this run the extraction energy of the proton beam was $1.2 \mathrm{GeV}$, with the magnets ramping at a constant value of $\dot{B}$. The peak-magnet current corresponded to a proton energy of $1.5 \mathrm{GeV}$. The proton-cycle repetition rate was $5 \mathrm{hz}$. The power and flicker measurements summarized in this report are based on a proton-cycle of $1.5 \mathrm{GeV}$ and $5 \mathrm{hz}$. Projections of power requirements and induced flicker for other cycles will be based on a $1.5 \mathrm{GeV}, 5 \mathrm{hz}$ cycle.

\section{$69 \mathrm{KV}$ Distribution System}

A site map of the $69 \mathrm{KV}$ distribution system is given in Figure 1. A quasi-network (oneline drawing) representation of the dedicated power line and transformer is given in Figure 2. In addition to the equivalent circuit and parameter values, Figure 2 lists the short-circuit

capacities (SCC) and the $\left(\frac{r}{x}\right)$ ratio of the three electrical ports that are required for an analysis of the impact of Booster power swing on the power grid. To minimize the impact of the Booster on the power grid, the coupling between the Booster and power grid is at the port with the lowest impedance level or highest short circuit capacity. 
In a reactive system, i.e., $\left(\frac{r}{x}\right)-0$, flicker is inversely dependent on the short circuit capacity of the port. In addition, amplitude flicker depends on the reactive power swing; phase flicker, on the real power swing. Corrections can be made for the $\left(\frac{r}{x}\right)$ ratio at the coupling ports.

The value of amplitude flicker can be calculated from the following expression:

$$
\frac{\Delta V}{V}=\frac{Q+P\left(\frac{r}{x}\right)}{S C C}
$$

and phase flicker from

$$
\Delta \theta=\frac{P-Q\left(\frac{r}{x}\right)}{S C C}
$$

$$
\begin{aligned}
& \text { where } \begin{array}{ll}
\mathrm{P} & =\text { real power } \\
\mathrm{Q} & =\text { reactive power } \\
\text { SCC } & =\text { short circuit capacity of the port } \\
\left(\frac{r}{x}\right) & =\text { ratio of resistance to reactance at the port }
\end{array}
\end{aligned}
$$

In these expressions $Q$ is positive for an inductive load and is negative for a capacitive load.

\section{Measurement of Power DC Bus}

Measurements of peak power and power swings can be obtained from both the DC bus and the AC bus. Reactive power swing must be obtained from the AC bus. Power measurements at the DC bus require the measurement of magnet current $i$ and magnet drivevoltage $v$ with a sampling storage oscilloscope. The product of $i$ and $v$, which is the DC power, is formed and displayed. Figure 3 is an oscillogram of magnet current and voltage for a single booster pulse. Figure 4 is an oscillogram of the DC pulsed-power over a five second interval. The scale factors for these oscillograms are: 


$\begin{array}{ll}\text { Current: } & 600 \mathrm{~A} / \text { volt } \\ \text { Voltage: } & 1000 \mathrm{~V} / \text { volt } \\ \text { Power: } & 0.6 \mathrm{MW} / \text { volt }^{2}\end{array}$

Figure 3 indicates two traces for voltage. The magnet drive-voltage is the sum of the two individual power supply voltages. Figure 4 gives the power flow for a supercycle of $3.8 \mathrm{sec}$. Each supercycle consists of five Booster cycles with a period of $0.2 \mathrm{sec} / \mathrm{cycle}$, and a single flattop cycle termed "User-3". The "User-3" cycle is used for Booster studies and has been formulated for different power levels. The 5-Booster cycles inject four triads of protons into the AGS, which is operated with a period of 3.8 seconds. The first Booster cycle initializes the magnet. The "User-3" cycle was used to study the effect of a large phase-back on the power grid.

From the oscillograms of Figures 3 and 4 the following electrical parameters are obtained for a Booster cycle:

Peak magnet current

Magnet drive voltage rectify invert

Peak power

rectify

invert

Peak power swing
2220 Amperes

4200 volts

3900 volts

9.11 MW

8.38 MW

17.49 MW

\section{Measurement of Power AC Bus}

Three phase power measurements at the $\mathrm{AC}$ bus were obtained by measuring the line current and phase-voltage of each phase. By multiplying the current and voltage in real time the power of each phase was obtained, which was then summed in real time to obtain the total power. A schematic depicting the measurement technique is given in Figure 5. The oscillograms in Figure 6 give the current and voltage of one Booster pulse for one of the three phases. The oscillogram in Figure 7A gives the power for the same phase. The time scale is the same for both oscillograms; 20 millisec/division.

In Figure 7A note that the power oscillates at $120 \mathrm{hz}$ or twice the power line frequency. Also, in Figure 7A, note the transition from rectify to invert $0.8 \mathrm{~cm}$ to the left of the vertical scale. This corresponds to one power line cycle. In this region the power goes from a positive to a negative value. Within the same time frame, note the widening of the current pulse in Figure 6. This widening delays the current by approximately $120^{\circ}$ to $135^{\circ}$, changing the sign of $p$ and introducing a large value of reactive current. 
The oscillograms of Figures 7B and 7C give the power from the other two phases. Also note the oscillations of $p$ about the horizontal-axis during the transition from rectify to invert. The large negative value of $p$ indicates a large value for the reactive power.

Figure 8 is an oscillogram of the real time sum of the individual phase-powers, i.e., $P_{A}(t)$ $+P_{B}(t)+P_{c}(t)$. Note that the net power is time invariant, i.e., the $120 \mathrm{hz}$ oscillations vanish, characteristic of a balanced 3-phase system.

In Figure 8 the scale factor is $4.608 \mathrm{MW} /$ volts $^{2}$. The peak powers are:

$\begin{array}{lr}\text { rectify } & 9.63 \mathrm{MW} \\ \text { invert } & 7.65 \mathrm{MW} \\ \text { swing } & 17.28 \mathrm{MW}\end{array}$

These numbers compare favorably with the values for power obtained from the DC bus.

The same data can be used to calculate the reactive power. The phase-voltage is delayed in real time to correspond to a phase shift of $86.4^{\circ}$ (nearly $90^{\circ}$ ) at the power line frequency, 60 hz. The delayed phase-voltage is multiplied by the line current for each phase and the three products are summed. The oscillogram in Figure 9 displays the real time solution to the second calculation. This is a plot of the reactive power. The scale factor in Figure 9 is also 4.608 $\mathrm{MW} /$ volts$^{2}$. The peak reactive powers during transition are

$\begin{array}{ll}\text { rectify } & 4.49 \text { MVAR, lag } \\ \text { invert } & 9.63 \text { MVAR, lag } \\ \text { swing } & 5.14 \text { MVAR, lag }\end{array}$

A discussion of 3-phase power measurements is included as Appendix A.

\section{Measurement of Flicker}

The technique utilized in calculating amplitude and phase flicker is described in Booster Tech. Note No. 73 "Spectrum Analysis of the Power Line Flicker Induced by the Electrical Test of the Prototype Booster Dipole". The frequency spectrum of the power line is recorded and interpreted in the time domain. The spectrum is characteristic of a modulated carrier; typically, an asymmetrical distribution of ordered-pairs of sidebands about a carrier.

The carrier is the power line frequency $(60 \mathrm{hz})$ and the sideband spacing is the machine supercycle period, $\frac{1}{3.8}-.263 . . . h z$. The AGS period of $3.8 \mathrm{sec}$ is derived from and is commensurate with the power line frequency. The frequency ratio between these two is (60 x 3.8) 228. The Booster cycle repetition rate of $5 \mathrm{~Hz}$ is also derived from the power line frequency and is commensurate with the supercycle period. The ratio between these two 
frequencies is 19 . The frequency spectrum is discrete and can be described by a Fourier Series. If these three frequencies were non-synchronous, the spectrum would be continuous and would require a Fourier Integral description.

The asymmetrical nature of the ordered-pairs of sidebands indicates that the signal is a combination of amplitude and angle (or frequency) modulation. In analyzing the spectrum each pair of sidebands is resolved into two different pairs of sidebands. One pair (As) is symmetrical with respect to the carrier and generates amplitude modulation. The other pair ( $\underline{A} q)$ termed antisymmetrical, is symmetrical with respect to the quadrature-phase of the carrier and generates angle modulation. If the complex values of the upper and lower sidebands are denoted by $\underline{B}_{1}$ and $\underline{\mathrm{B}}_{2}$, then

$$
\begin{gathered}
A s=\frac{\underline{B_{1}}+\underline{B_{2}^{*}}}{2} \\
A q=\frac{\underline{B}_{1}-\underline{B}_{2}^{*}}{2}
\end{gathered}
$$

where $\underline{\mathrm{B}}_{2}^{*}$ is the complex conjugate of $\underline{\mathrm{B}}_{2}$.

The spectrum has a width of $20 \mathrm{~Hz}( \pm 10 \mathrm{~Hz}$ about $60 \mathrm{~Hz})$, with a sideband spacing of $1 / 3.8 \mathrm{~Hz}$. Thus thirty-eight ordered-pairs of sidebands can be recovered from a typical spectrum. All the symmetrical sidebands are combined in one Fourier series $I(t)$ that is in phase with the carrier. All anti-symmetrical sidebands are combined in a second Fourier series $Q(t)$ that is in quadrature phase with the carrier.

$$
\begin{aligned}
& I(t)=2 \sum_{j=1}^{38} A_{s j} \cos \left[2 \pi j F t+\theta_{s j}\right] \\
& Q(t)=2 \sum_{j=1}^{38} A_{q j} \cos \left[2 \pi j F t+\theta_{q j}\right]
\end{aligned}
$$

where $\mathrm{F}=$ sideband spacing

$\begin{aligned} & \text { As } \\ & \text { Aq }\end{aligned}=$ amplitude of symmetrical or quadrature sideband

$\left.\begin{array}{c}\theta s \\ \theta q\end{array}\right\}=$ phase of symmetrical or quadrature sideband 
Amplitude flicker $\left(\frac{\Delta V}{V}\right)$ depends on $I(t)$ :

$$
\frac{\Delta V}{V}=\frac{\text { peak-peak value of } I(t)}{V} .
$$

Phase flicker $\Delta \theta$ depends on $\mathrm{Q}(\mathrm{t})$ :

$$
\Delta \theta-\frac{\text { peak-peak value of } Q(t)}{V} \text { radians. }
$$

where $\mathrm{V}=$ magnitude of the $60 \mathrm{~Hz}$ spectral line.

A typical spectrum showing both magnitude and phase is given in Figure 10. This was recorded from the $13.8 \mathrm{Kv}$ line feeding the Booster. Figure 11 is a plot of $\mathrm{I}(\mathrm{t})$ and Figure 12 is a plot of $\mathrm{Q}(\mathrm{t})$. Note the distinctive signature of the Booster in Figures 11 and 12 ; the 5Booster cycles followed by "User 3". These plots are for a time duration of 4 seconds. The plots are periodic, with a period of 3.8 seconds. Note the inverse relationship between the sideband spacing $\frac{1}{3.8}-.263 \ldots . . . . H z$ and the periodicity of 3.8 seconds, which is the foundation of the Fourier series expansion.

In examining the flicker waveforms it is observed that the phase flicker (Fig. 12) oscillates about an average value and that the amplitude flicker (Fig. 11) is unidirectional. The real power flow changes sign from a positive to a negative value as the power supplies change modes from rectify to invert. The phase flicker $\Delta \theta$ follows the sign of power flow. Since the rectifier-banks are controlled by delay of the firing of the SCR diodes, the power supplies operate with variable lag angles in both the rectify and invert mode. The reactive power flow is unidirectional.

Independently of flicker calculations, it can be shown that power flow, both direction and magnitude, depends on the phase-shift (or electrical power angle) between the load and power grid. ${ }^{1}$

$$
P=\frac{V_{1} V_{2}}{X} \sin \delta
$$

where $P$ - power flow

$V_{1}, V_{2}=r m s$ voltage of grid and load

$\delta$ - phase shift between load and grid voltages

$X$ - reactance of port.

1. J.G. Tarboux, Introduction to Electric Power Systems, International Textbook Company, 1944, p.269. 
For a passive load (energy transfer is from the power grid to load) the load voltage lags the power grid voltage; for an active load (energy transfer is from the load to power-grid) the load voltage leads the power-grid voltage.

\section{Results of Flicker Measurements}

The frequency spectrum was recorded from the $13.8 \mathrm{Kv}$ line at transformer $\# 7$ (Booster feed) and from the 480 volt line on the lab site. Figures 13 and 14 are plots of $I(t)$ and $Q(t)$, amplitude and phase flicker, on the 480 volt line. These measurements are essentially the same as would be induced at the LILCO/BNL $69 \mathrm{Kv}$ port. Measurements of the primary $(69 \mathrm{Kv})$ side of transformer $\# 7$ were not permitted at this time.

A summary of the measured, calculated, and projected amplitude and phase flicker is given in Table I. Calculated values are based on measured power (real and reactive) levels and parameters of the $69 \mathrm{Kv}$ and $13.8 \mathrm{Kv}$ power distribution system on the lab site. Projected flicker values are from Tech. Note No. 45.

\begin{tabular}{||c|l|c|c|c||}
\cline { 3 - 5 } \multicolumn{2}{c|}{} & Booster 13.8 Kv Feed & Lab Site & Reduction Ratio \\
\hline \hline \multirow{4}{*}{\begin{tabular}{c} 
Phase Flicker \\
\cline { 2 - 5 }
\end{tabular}} & Measured & $3.78^{\circ}$ & $.39^{\circ}$ & 9.69 \\
\cline { 2 - 5 } & Calculated & $3.88^{\circ}$ & $.41^{\circ}$ & 9.46 \\
\cline { 2 - 5 } $\begin{array}{c}\text { Amplitude } \\
\text { Flicker }\end{array}$ & Projected & $3.96^{\circ}$ & $.39^{\circ}$ & 10.15 \\
\cline { 2 - 6 } & Measured & $2.4 \%$ & $.28 \%$ & 8.57 \\
\cline { 2 - 6 } & Calculated & $3.0 \%$ & $.33 \%$ & 9.09 \\
\cline { 2 - 6 } & Projected & $1.97 \%$ & $.17 \%$ & 11.59 \\
\hline
\end{tabular}

TABLE I

Summary of Flicker Values at the Dedicated $13.8 \mathrm{Kv}$ Booster Line and on the Lab Site

\section{Short Circuit Capacity}

at the LILCO Substation 2310 MVA

at the $13.8 \mathrm{Kv}$ Bus $246 \mathrm{MVA}$

ratio is 9.39

In general, the phase-flicker values are in close agreement. The measured amplitude flicker values are larger than the projected values, which indicates that the magnet power supplies are operating with a greater phase-back, resulting in a greater reactive-power swing than was utilized in the original calculations. The calculated value of amplitude flicker is approximately $20 \%$ greater than the measured value. This indicates a possible discrepancy of the same value, $20 \%$, in the measured value of reactive power. 
Flicker measurements, derived from an analysis of the frequency spectrum, allows a separation of the various sources of the pulsed power by its periodicity, characterized as a signature. In addition to the Booster Power Supply the Booster RF System, the AGS RF System, kicker magnet power supplies, and the LINAC are pulsed at the supercycle rate. The AC power for these systems are through the primary feeder, LILCO 69-863 and 69-858 and contributes to the flicker at the LILCO/BNL port in direct proportion to its power swing. At the dedicated $13.8 \mathrm{Kv}$ Booster feed these additional pulsating sources contribute to the flicker in proportion to $1 / 10$ of the power swing. The ratio of $1 / 10$ is the ratio of SCC of the two ports. It is estimated that the additional pulsating power is in the range of $2 \mathrm{MW}$. The additional flicker on the Lab site is in the range of $12 \%$, which at the dedicated $13.8 \mathrm{Kv}$ port is $1.2 \%$.

The phase flicker waveform of the 480 volt line is dominated by a large low frequency component. The induced flicker of the Booster and "User-3" cycles is linearly additive to this low frequency component. The frequency spectrum of the power line with the Booster, AGS, Linac and NSLS off was recorded and analyzed. The analysis indicates a similar low frequency waveform. This waveform has a frequency of approximately $0.15 \mathrm{~Hz}$ and a phase variation of approximately $0.9^{\circ}$. The origin of the background waveform is under investigation. At the time of this writing, it is believed that the background is due to deviation of the power grid frequency caused by hunting of the unit (generator) governors. The governors attempt to maintain a constant frequency as the system load fluctuates. A similar background waveform is observed in the other flicker waveforms. The results of this study will be reported in a second technical note, dealing with the quality of the electrical power system.

\section{Projections}

It is proposed to increase the Booster pulse repetition rate from $5 \mathrm{~Hz}$ to $7.5 \mathrm{~Hz}$. By frequency scaling of the magnet ramp rate, the peak power swing would increase by a factor of 1.5 to $26.3 \mathrm{MW}$. The Booster Design Manual specifies a total magnet ramp time, the sum of rectify and invert time, of 90 milliseconds. For these measurements the total magnet ramp time was 120 milliseconds, thus, the peak power swing would increase by a factor of 1.33 to 23.3 MW. It has also been proposed to increase the proton energy from $1.5 \mathrm{GeV}$ to $2.0 \mathrm{GeV}$. The increase in magnet current has been calculated as a function of proton energy. ${ }^{2}$

\section{Proton Energy $(\mathrm{GeV})$}

1.2

1.5

1.7

1.8

2.0

\section{Magnet Current (Amperes)}

1916

2245

2465

2564

2774

2. Memo from Kenneth Reece dated October 21, 1992. 
The increase in power swing has been projected and is scaled as the square of the magnet current.

As a function of the upgraded Booster performance the following flicker values on the lab site have been calculated and are included in Table II. Corrections have been made for the pulsed power from the primary feed.

TABLE II

Summary of Power Swing and Site Flicker for Upgraded Booster Performance

\begin{tabular}{|c|c|c|c|c|c|}
\hline & Proton Energy & $\begin{array}{c}\text { Proton Pulse } \\
\text { Repetition Rate }\end{array}$ & $\begin{array}{c}\text { Peak } \\
\text { Power Swing }\end{array}$ & $\begin{array}{l}\text { Amplitude } \\
\text { Flicker }\end{array}$ & $\begin{array}{l}\text { Phase } \\
\text { Flicker }\end{array}$ \\
\hline $\begin{array}{c}\text { Base } \\
\text { Measurement }\end{array}$ & $1.5 \mathrm{GeV}$ & $5 \mathrm{~Hz}$ & 17.5 MW & $.28 \%$ & $.39^{\circ}$ \\
\hline $\begin{array}{l}\text { Corrected for } \\
\text { Pulsed Pow- } \\
\text { er on } \\
\text { Primary } \\
\text { Feed }\end{array}$ & $1.5 \mathrm{GeV}$ & $5 \mathrm{~Hz}$ & $17.5 \mathrm{MW}$ & $.25 \%$ & $.35^{\circ}$ \\
\hline Projection & $\begin{array}{l}1.5 \mathrm{GeV} \\
1.5 \mathrm{GeV} \\
2.0 \mathrm{GeV} \\
2.0 \mathrm{GeV} \\
2.0 \mathrm{GeV} \\
\end{array}$ & $\begin{array}{l}7.5 \mathrm{~Hz} \\
7.5 \mathrm{~Hz} \\
5.0 \mathrm{~Hz} \\
7.5 \mathrm{~Hz} \\
7.5 \mathrm{~Hz}\end{array}$ & $\begin{array}{l}23.3 \mathrm{MW} \\
26.3 \mathrm{MW} \\
26.7 \mathrm{MW} \\
35.3 \mathrm{MW} \\
\text { 40.1 MW }\end{array}$ & $\begin{array}{l}.37 \% \\
.41 \% \\
.42 \% \\
.54 \% \\
.61 \% \\
\end{array}$ & $\begin{array}{l}.52^{\circ} \\
.58^{\circ} \\
.58^{\circ} \\
.75^{\circ} \\
.85^{\circ} \\
\end{array}$ \\
\hline $\begin{array}{c}\text { Tech. Note } \\
54\end{array}$ & $1.5 \mathrm{GeV}$ & $7.5 \mathrm{~Hz}$ & $22 \mathrm{MW}$ & $.30 \%$ & $.55^{\circ}$ \\
\hline
\end{tabular}

Table II summarizes the impact of Booster power swing on the power distribution system on the lab site during the last run (June - July 1992). The table is corrected for an additional $2 \mathrm{MW}$ of pulsed power from the primary feed. It also projects the impact on the power system as the Booster performance is upgraded by an increase in proton energy and an increase in repetition rate. Two values for peak power swing have been calculated for each cycle with a $7.5 \mathrm{~Hz}$ pulse repetition rate. The values for peak power swing depend on the magnet ramp time.

Projection Line One: $\quad$ As specified in the Booster Design Manual for the $1.5 \mathrm{GeV}-7.5 \mathrm{~Hz}$ cycle, 90 millisecond ramp time.

Projection Line Two: $\quad$ Direct frequency scaling of the Booster $5 \mathrm{~Hz}$ cycle, 80 millisecond ramp time. 
The values in Table II are compared with the values in Booster Tech. Note No. 54 "Calculation of Booster Power Requirements and Power Line Flicker of $1.5 \mathrm{GeV}$ Proton Operation". The flicker values from Tech. Note No. 54 have been corrected for the additional pulsed power from the primary feed.

Guided by the data of Table II, an absolute limiting value for the peak power swing can be established. The limit is based on the maximum allowable amplitude flicker value of $0.5 \%$. This corresponds to an absolute peak power swing of $32 \mathrm{MW}$. Practically the peak power swing is $28-30 \mathrm{MW}$. For the Booster design value of $1.5 \mathrm{GeV}-7.5 \mathrm{~Hz}$ the peak power swing is approaching the limit of the presently configurated power distribution system. The Booster can be upgraded to a $2.0 \mathrm{GeV}-5 \mathrm{~Hz}$ cycle but cannot be upgraded to a 2.0 $\mathrm{GeV}-7.5 \mathrm{~Hz}$ cycle.

Consideration has been given to using the $69 \mathrm{KV}$ alternate feed with additional substation transformers to expand the lab power distribution system. The short circuit capacity of the $69 \mathrm{KV}$ alternate feed electrical port is $68 \%$ of the short circuit capacity of the LILCO-BNL port. Based on an upgrade of Booster performance the amplitude flicker at the alternate feed port is in the range of $0.65-.75 \%$ and the phase flicker is in excess of $1^{\circ}$. These flicker levels would severely limit the loads that can be energized from this port. 


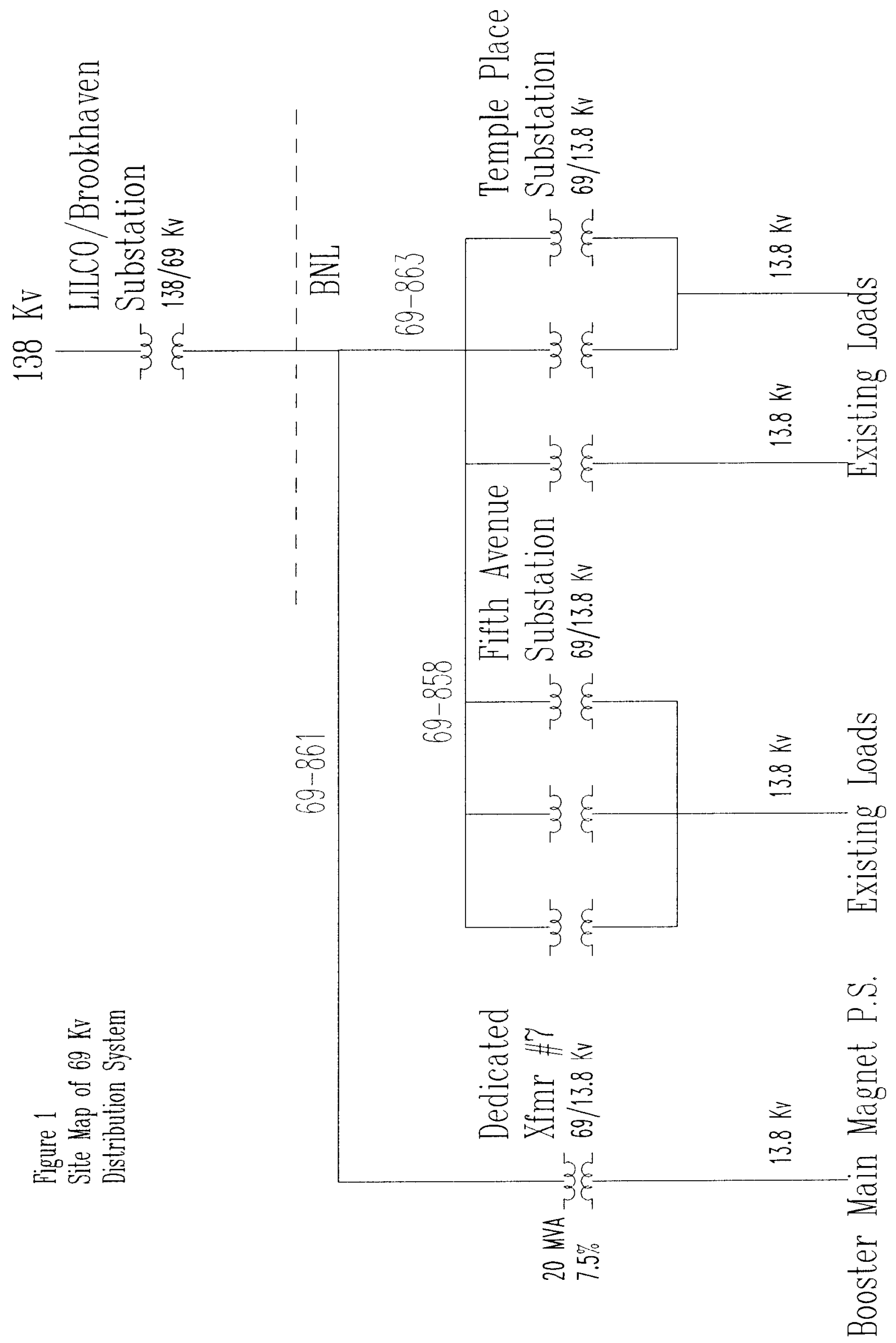




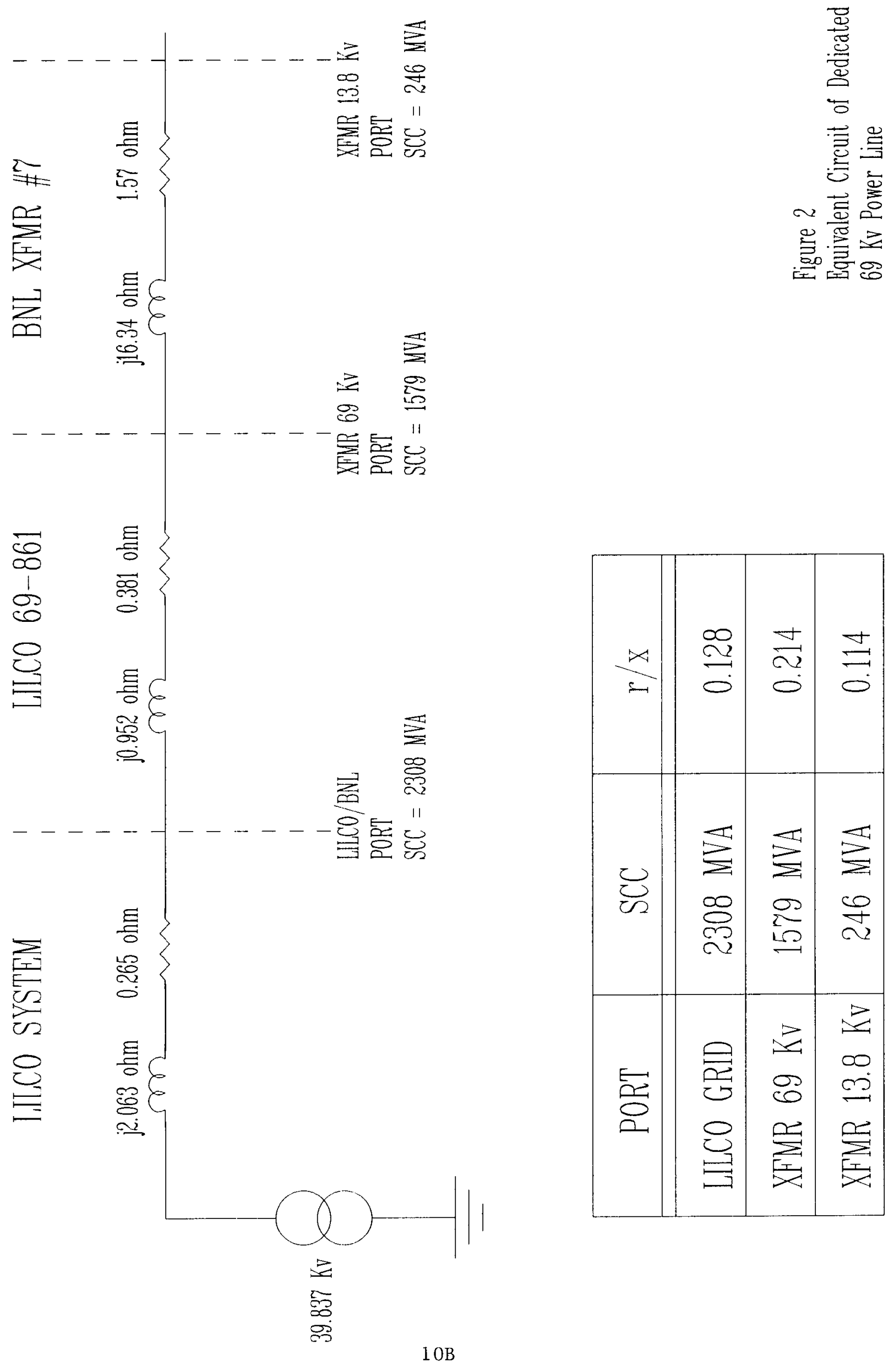




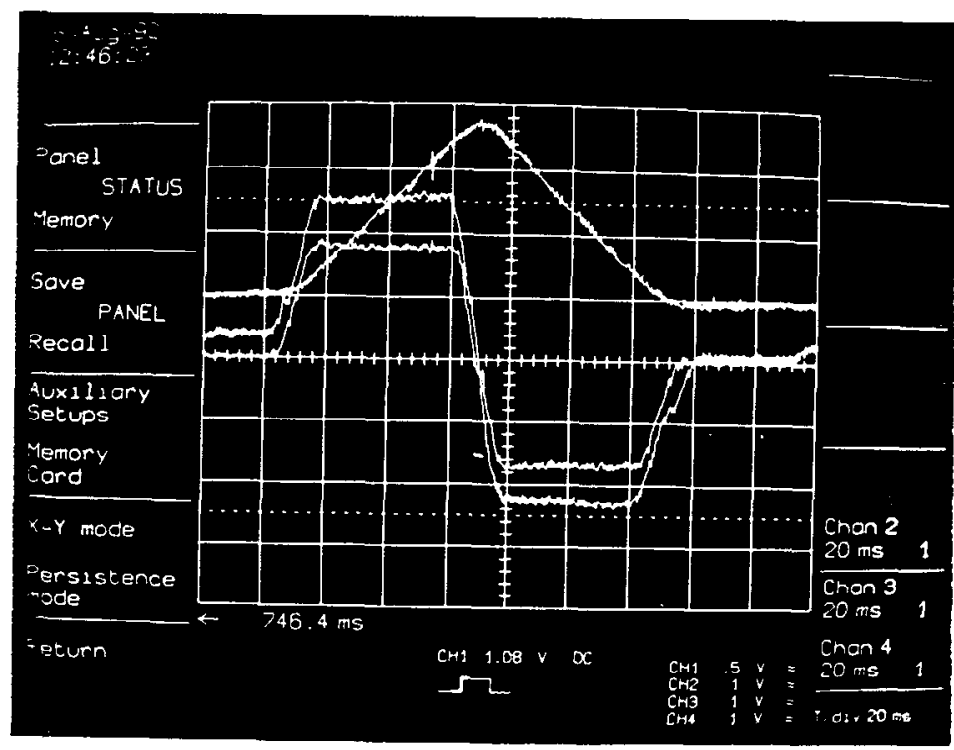

Figure 3

Oscillogram of Magnet Current and Voltage

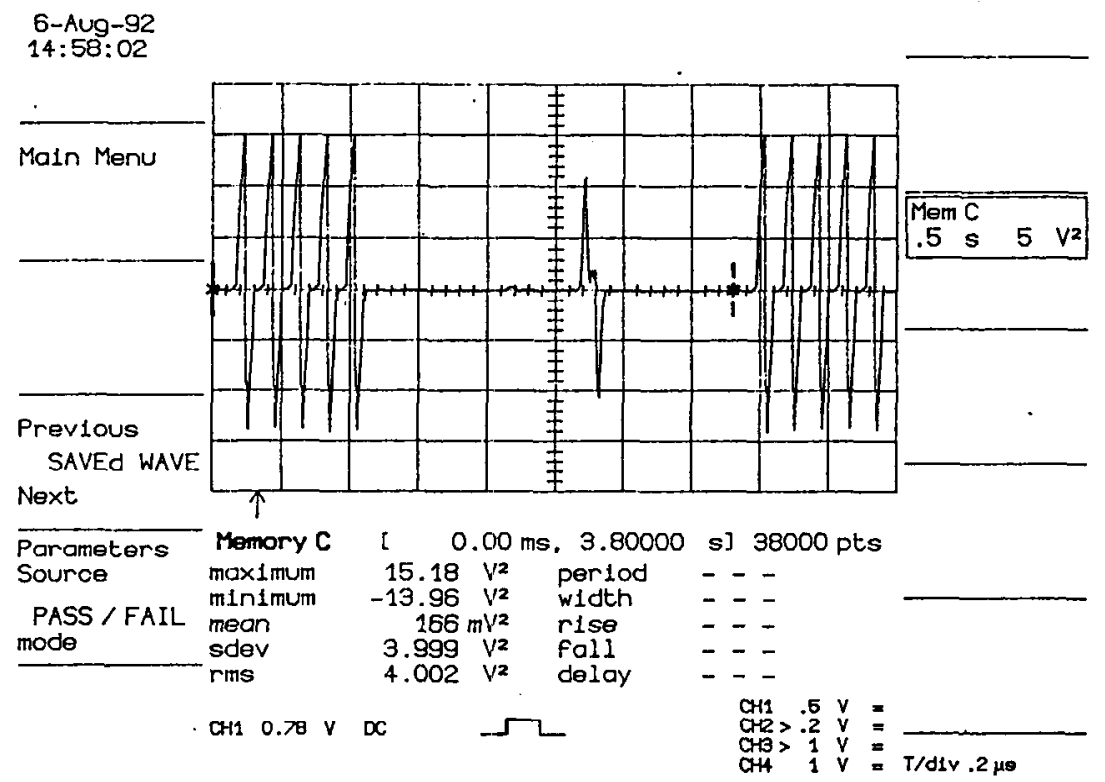

Figure 4

Oscillogram of Magnet Power 


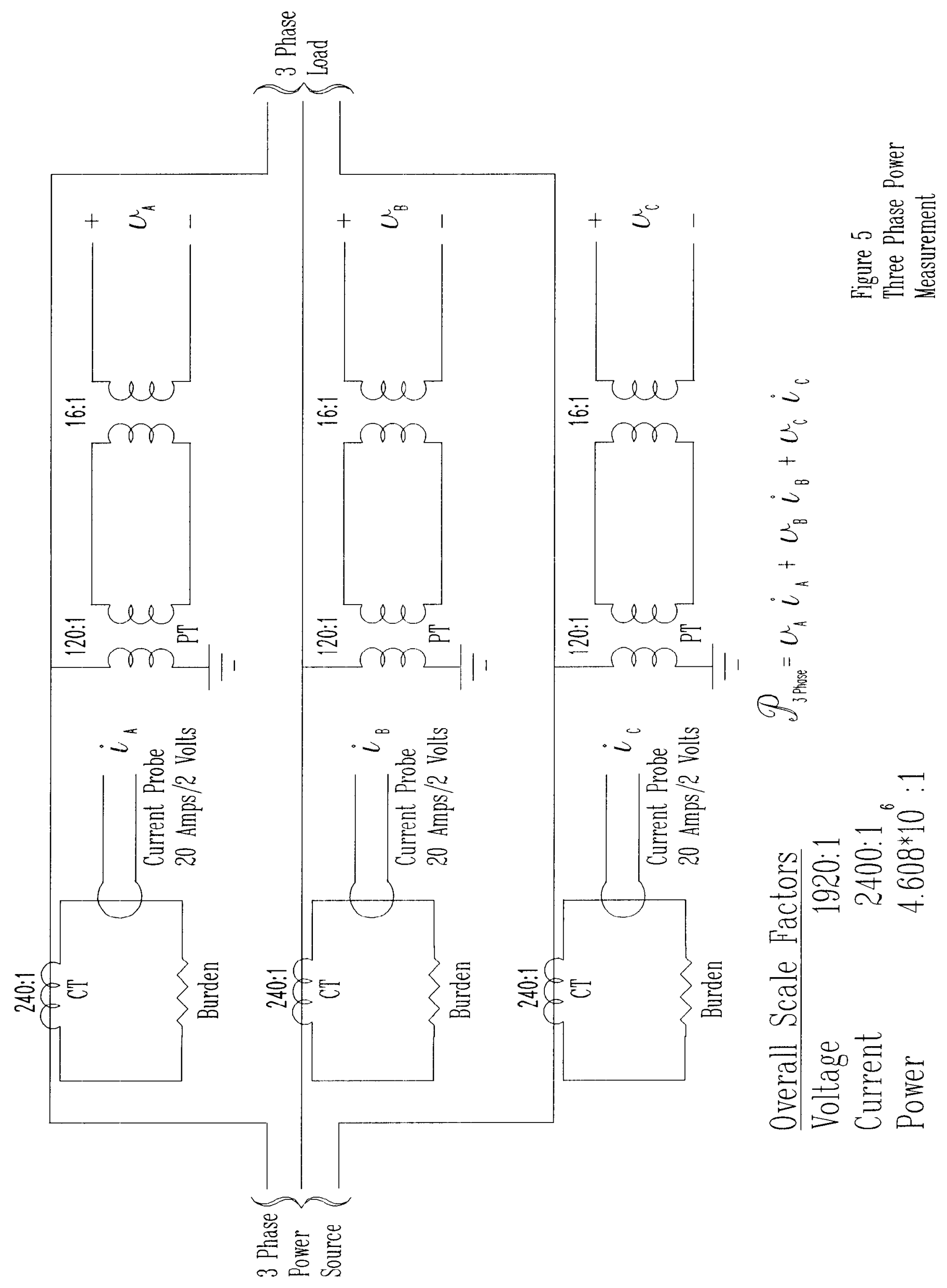




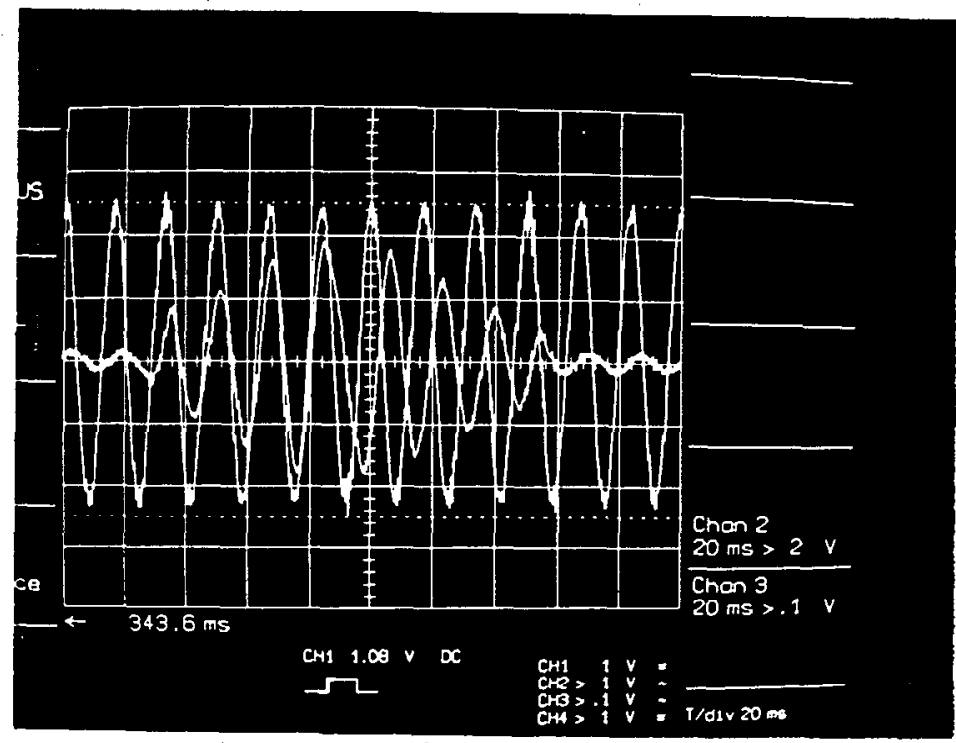

Figure 6

Oscillogram of line Current and Phase Voltage (Phase A)

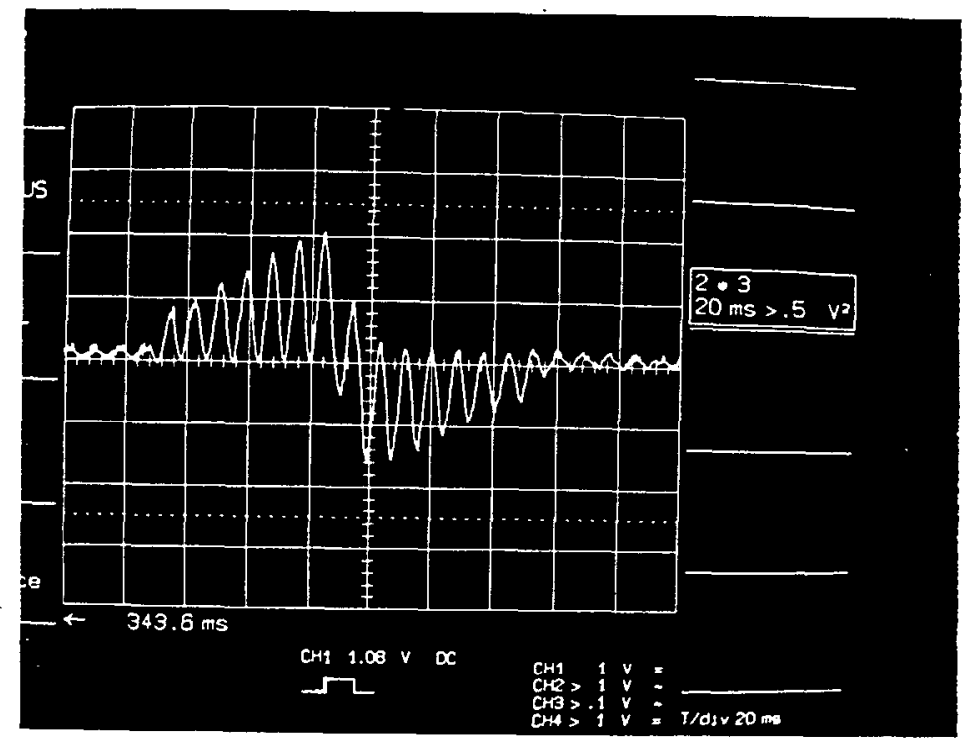

Figure 7A

Oscillogram of Power

(Phase A)

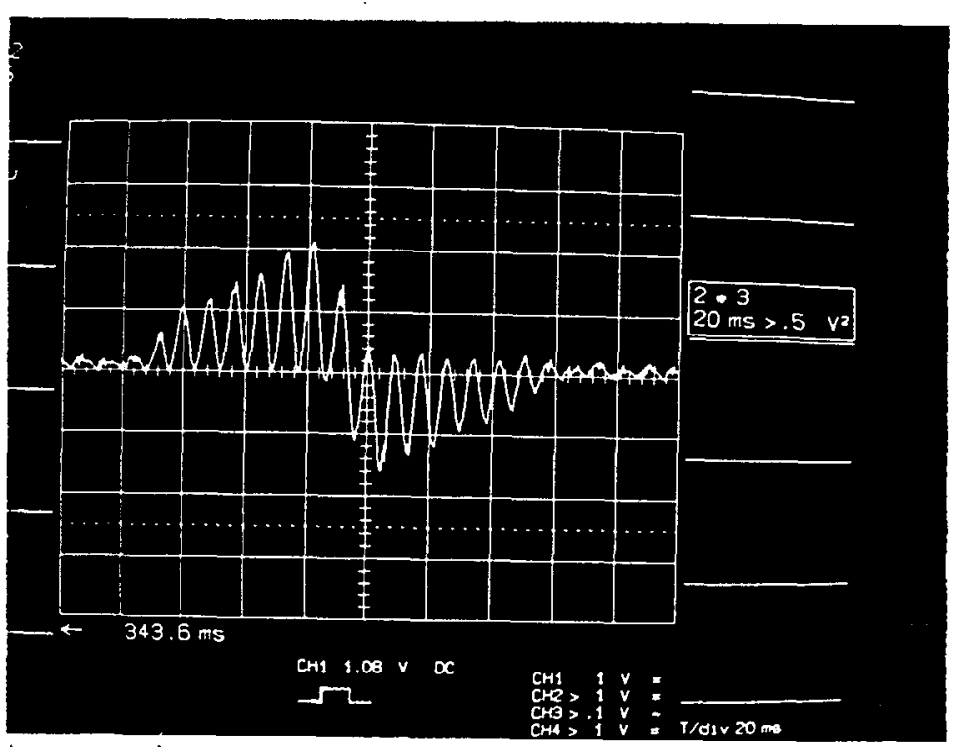

h

Figure 7B

Oscillogram of Power

(Phase B)

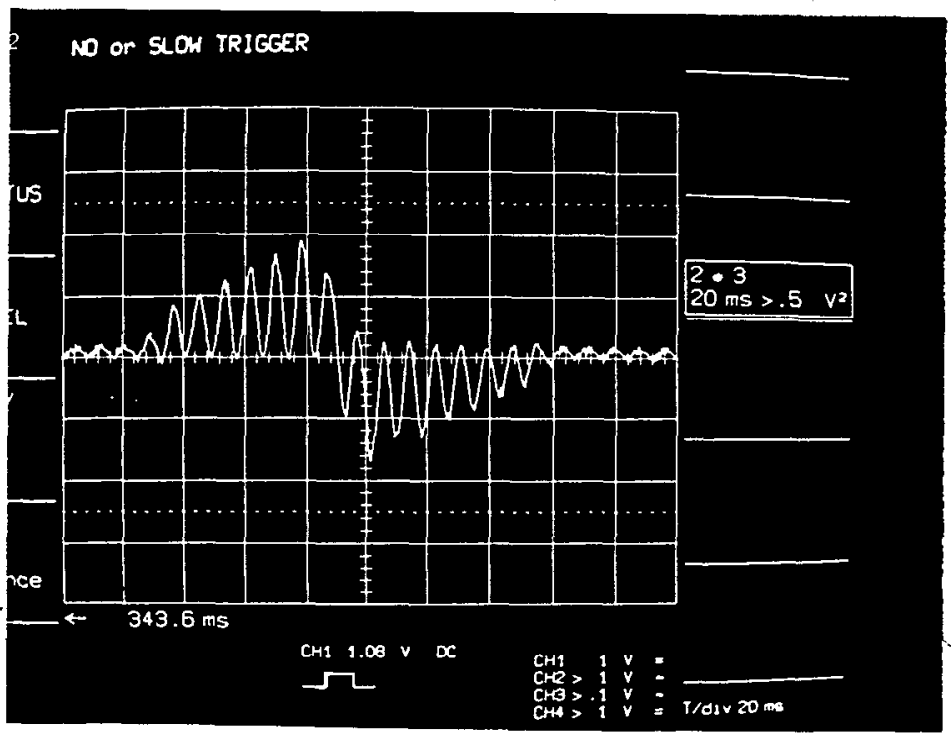

Figure $7 \mathrm{C}$

Oscillogram of Power

(Phase C) 


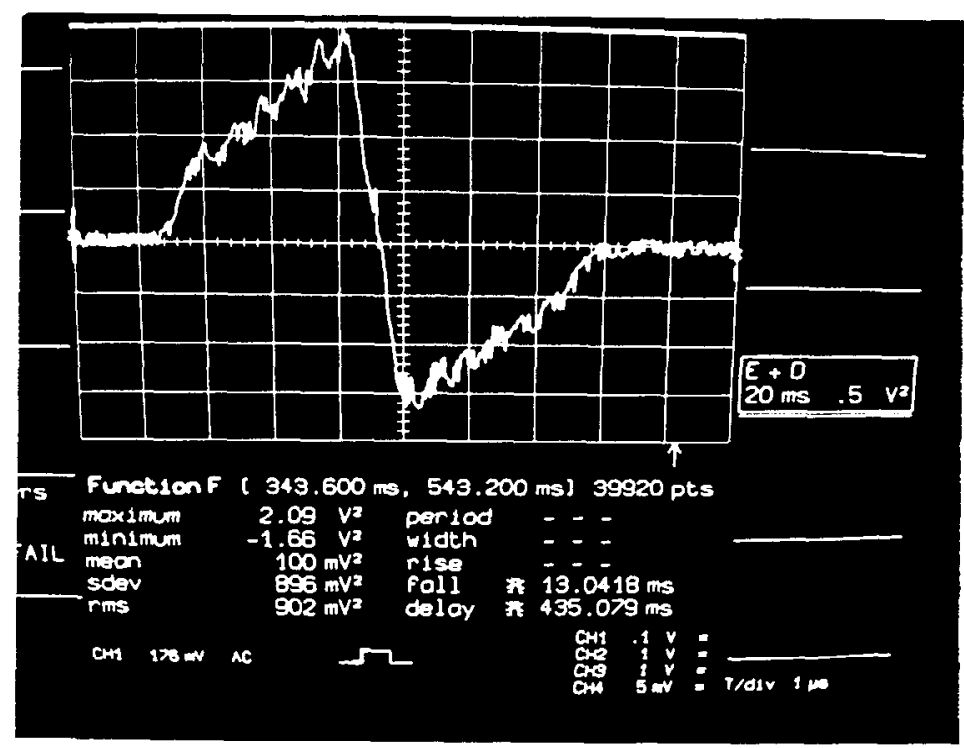

Figure 8

Oscillogram of Three Phase Power (Sum of $P_{A}, P_{B}$, and $P_{C}$ )

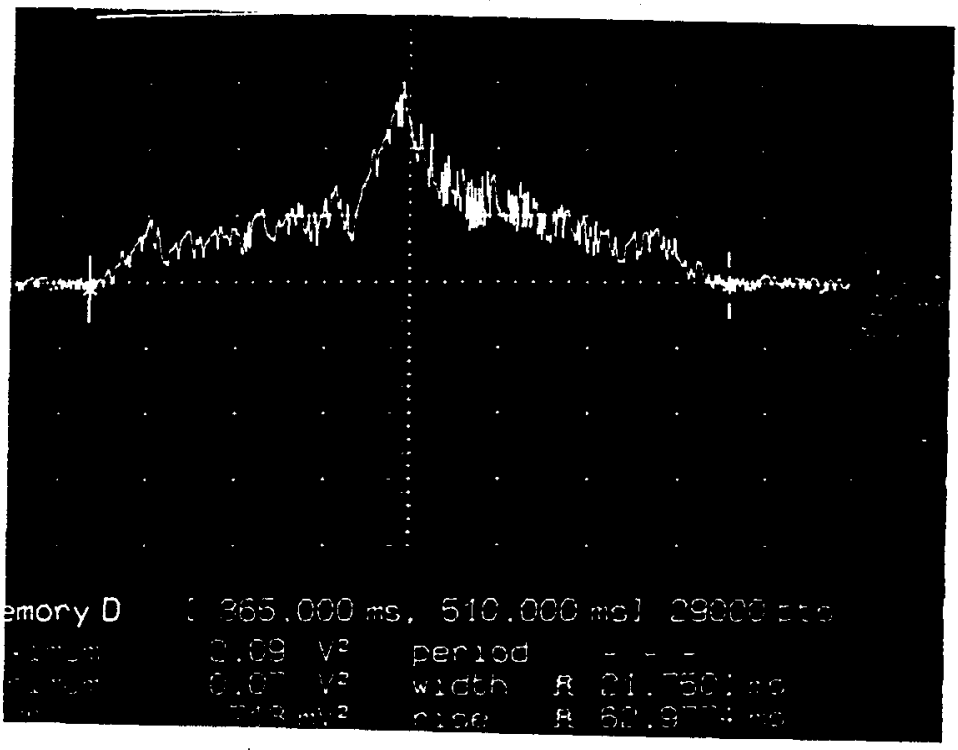

Figure 9

Oscillogram of Reactive Power 


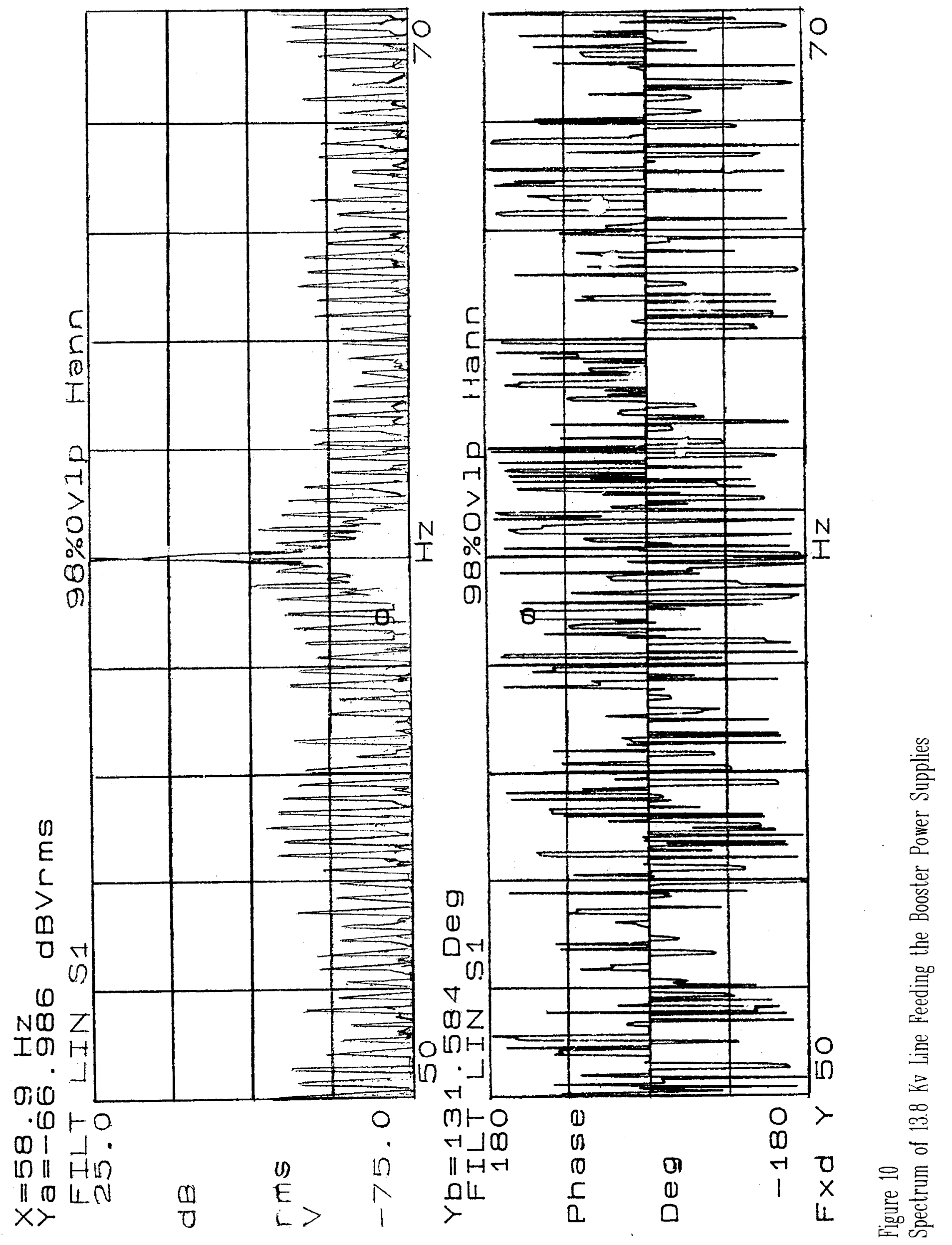


Figure 11

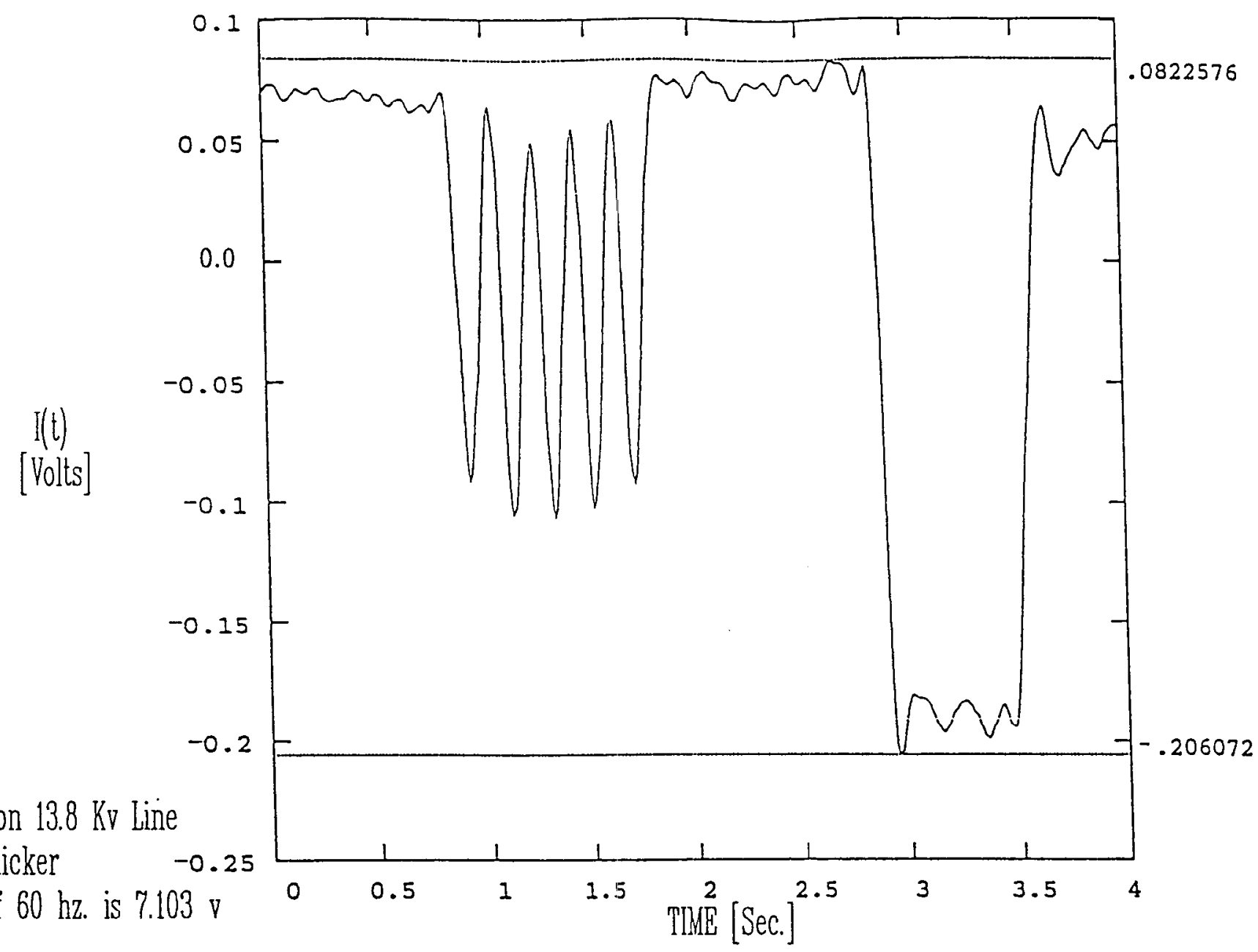

Plot of $\mathrm{I}(\mathrm{t})$ on $13.8 \mathrm{Kv}$ line

Amplitude Flicker

Nagnitude of $60 \mathrm{hz}$. is $7.103 \mathrm{v}$

${ }^{2}{ }^{2}[\mathrm{Sec} .]^{2 .}$

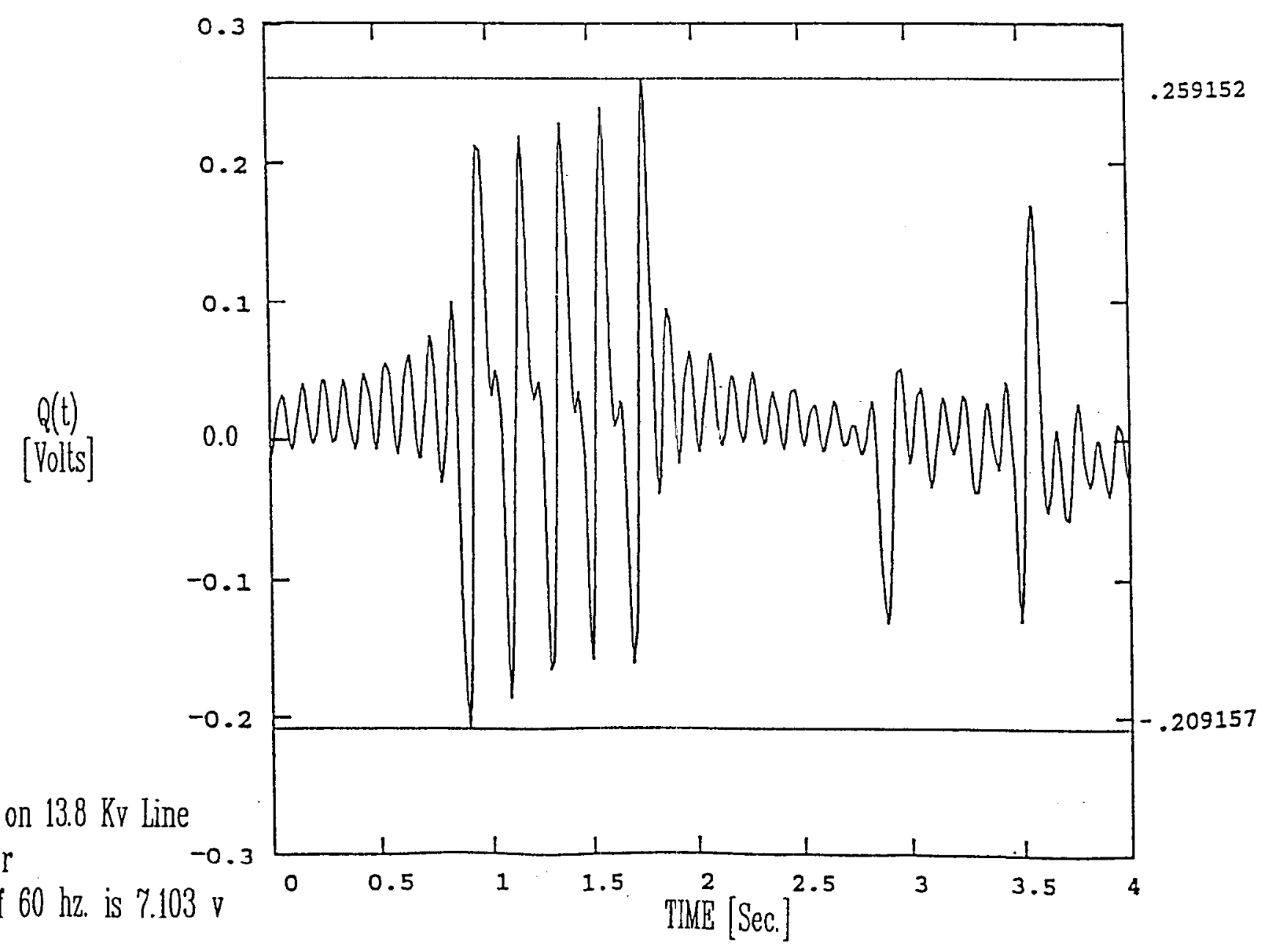

Figure 12

Plot of $Q(t)$ on $13.8 \mathrm{Kv}$ line

Phase Flicker

Magnitude of $60 \mathrm{hz}$, is 7.103 v 
Figure 13

I(t)
$[$ Volts]

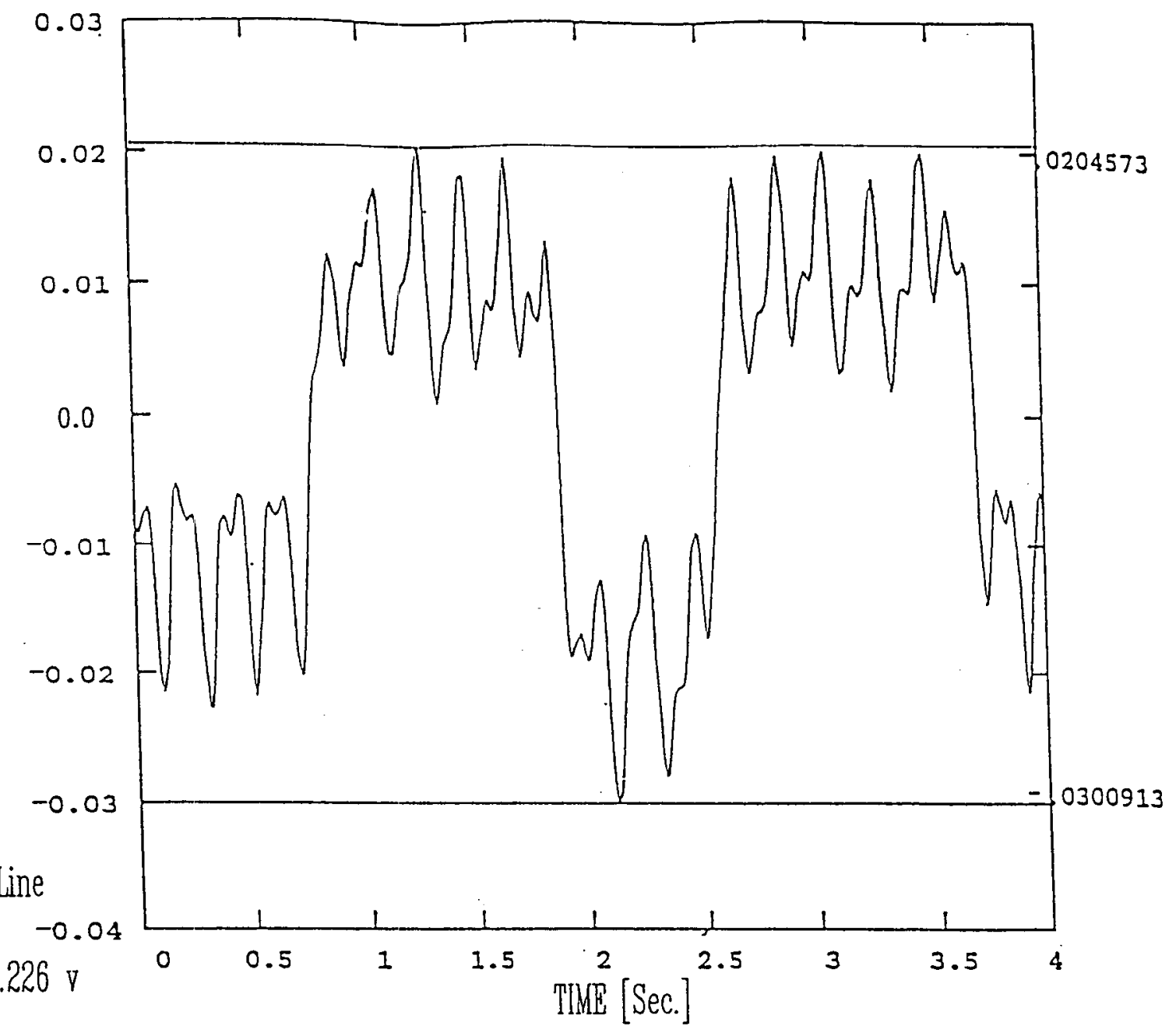

Plot of $I(t)$ on 480 Volt line

Amplitude Flicker

Magnitude of $60 \mathrm{hz}$. is 7.226

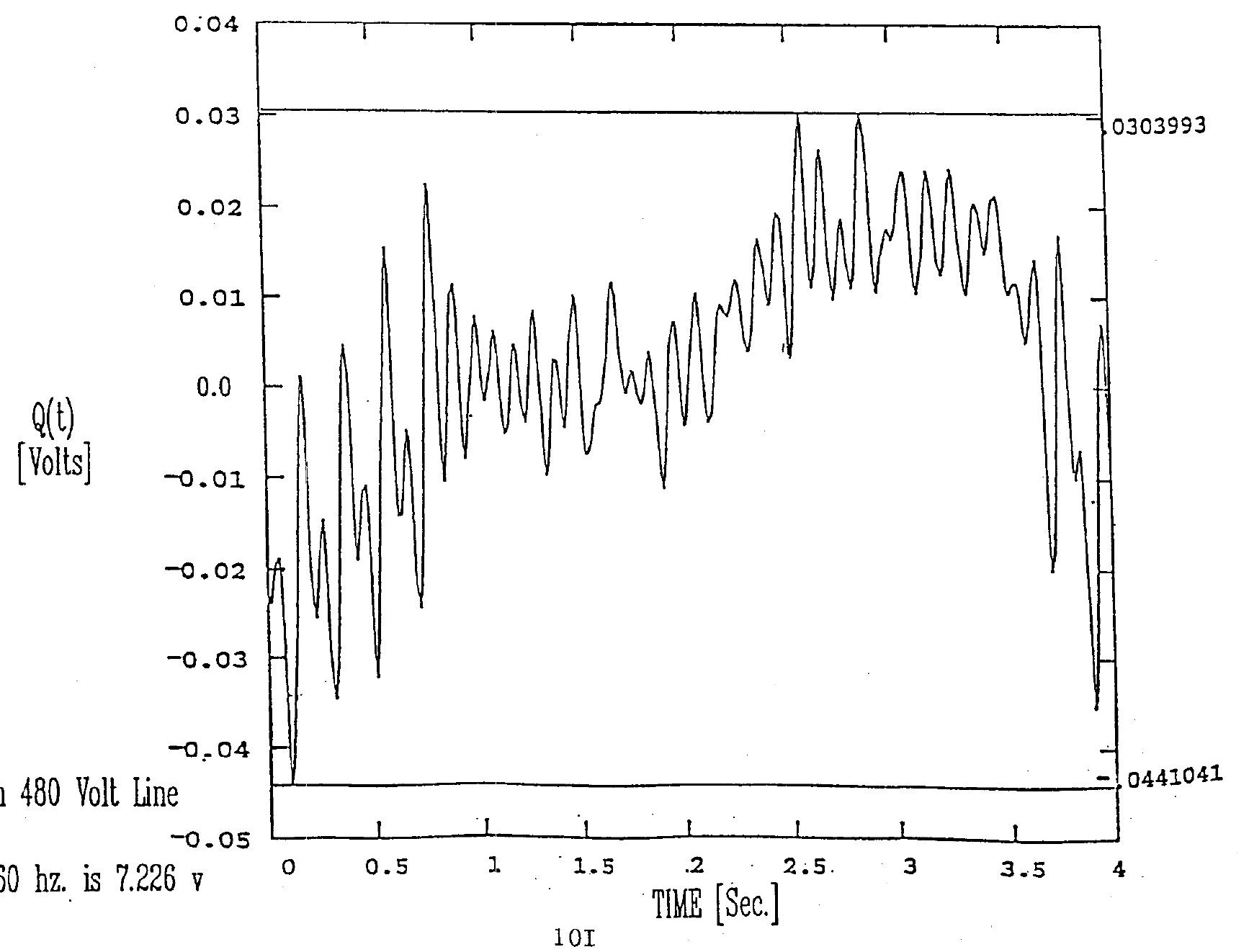

Figure 14

Plot of $Q(t)$ on 480 Volt line

Phase Flicker

Magnitude of $60 \mathrm{hz}$. is $7.226 \mathrm{v}$ 


\section{APPENDIX A}

\section{3-PHASE POWER MEASUREMENTS}

Instantaneous power at the 3-phase AC bus is measured with a two step procedure:

First, multiply the phase-voltage by the line current in real time for each of the three phases. Each product is equal to the instantaneous phase power.

Second, sum the three products in real time to give the instantaneous 3-phase power flow. For a balanced 3-phase load, the power flow which is formed from the sum of the three products is time invariant. The $120 \mathrm{~Hz}$ power fluctuations in each of the three phases are $120^{\circ}$ out of phase and sum to zero.

Consider the calculation of power in one of the three phases. The phase voltage $\nu_{\mathrm{A}}$ is $\mathrm{V}$ sin $\omega t$ and the line current $i_{A}$ is $I \sin (\omega t-\theta)$, where $\theta$ is the angle by which $i_{A}$ lags $\nu_{A}$. The product of $i_{A}$ and $\nu_{A}$ is the instantaneous power flow $P_{A}(t)$ of phase $A$, and is given by

$$
\begin{aligned}
P_{A}(t) & =V I \sin \omega t \sin (\omega t-\theta) \\
& =1 / 2 \text { VI } \cos \theta-1 / 2 \text { VI } \cos \theta \cos 2 \omega t-1 / 2 \text { VI } \sin \theta \sin 2 \omega t
\end{aligned}
$$

Recognizing that

$$
\begin{aligned}
& 1 / 2 \mathrm{VI} \cos \theta=\mathrm{P} \\
& 1 / 2 \mathrm{VI} \sin \theta=\mathrm{Q}
\end{aligned}
$$

where $\mathbf{P}$ is the average value of real power flow

$\mathrm{Q}$ is the average value of reactive power flow

$P_{A}(t)$ can be formulated as:

$$
\begin{aligned}
\mathrm{P}_{\mathrm{A}}(\mathrm{t}) & =\mathrm{P}-[\mathrm{P} \cos 2 \omega \mathrm{t}+\mathrm{Q} \sin 2 \omega \mathrm{t}] \\
& =\mathrm{P}-\sqrt{\mathrm{P}^{2}+\mathrm{Q}^{2}} \cos [2 \omega \mathrm{t}-\theta]
\end{aligned}
$$

In a balanced 3-phase system the net power is given by

$$
\begin{aligned}
\mathrm{P}(\mathrm{t})= & \mathrm{P}_{\mathrm{A}}(\mathrm{t})+\mathrm{P}_{\mathrm{B}}(\mathrm{t})+\mathrm{P}_{\mathrm{C}}(\mathrm{t}) \\
& =\mathrm{P}-\sqrt{\mathrm{P}^{2}+\mathrm{Q}^{2}} \cos [2 \omega \mathrm{t}-\theta]+\mathrm{P} \\
& -\sqrt{\mathrm{P}^{2}+\mathrm{Q}^{2}} \cos \left[2 \omega \mathrm{t}-\theta-240^{\circ}\right]+\mathrm{P}-\sqrt{\mathrm{P}^{2}+\mathrm{Q}^{2}} \cos \left[2 \omega \mathrm{t}-\theta+240^{\circ}\right]
\end{aligned}
$$

Since $\sin \alpha+\sin \left(\alpha-120^{\circ}\right)+\sin \left(\alpha+120^{\circ}\right) \equiv 0$

then

$$
\mathrm{P}(\mathrm{t})=3 \mathrm{P}=3 / 2 \mathrm{VI} \cos \theta .
$$


The measuring system depicted in Figure 5 is employed to measure the instantaneous phase-power and the instantaneous value of 3-phase power flow.

Reactive power is measured with the same system which was used to measure real power. The measured value of phase voltage $\nu_{A}$ is delayed by $90^{\circ}$. The measured value of $i_{A}$ is multiplied in real time by the delayed value of $\nu_{\mathrm{A}}$.

For a single phase circuit the reactive power is given by:

$$
\begin{aligned}
\mathrm{Q}_{\mathrm{A}}(\mathrm{t}) & =\mathrm{VI} \sin \left(\omega \mathrm{t}-90^{\circ}\right) \sin (\omega \mathrm{t}-\theta) \\
& =1 / 2 \mathrm{VI} \sin \theta+1 / 2 \mathrm{VI} \sin \theta \cos 2 \omega \mathrm{t}-1 / 2 \mathrm{VI} \cos \theta \sin 2 \omega \mathrm{t} \\
& =\mathrm{Q}+\mathrm{Q} \cos 2 \omega \mathrm{t}-\mathrm{P} \sin 2 \omega \mathrm{t} \\
& =\mathrm{Q}-\sqrt{\mathrm{Q}^{2}+\mathrm{P}^{2}} \sin (2 \omega \mathrm{t}-\theta) .
\end{aligned}
$$

For a balanced 3-phase system the net reactive power is

$$
\mathrm{Q}(\mathrm{t}) \quad=3 \mathrm{Q}=3 / 2 \mathrm{VI} \sin \theta .
$$

Reactive power can also be inferred from the single-phase power measurement $P_{A}(t)$. Denoting the maximum value of $P_{A}(t)$ by $P$ and the minimum value of $P_{A}(t)$ by $\underline{P}$, thus:

$$
\begin{aligned}
& \overrightarrow{\mathbf{P}}=\mathrm{P}+\sqrt{\mathrm{P}^{2}+\mathrm{Q}^{2}} \\
& \underline{\mathbf{P}}=\mathbf{P}-\sqrt{\mathrm{P}^{2}+\mathrm{Q}^{2}}
\end{aligned}
$$

Solving these expressions for $\mathrm{P}$ and $\mathrm{Q}$, yield

$$
\begin{gathered}
P=\frac{\bar{P}+P}{2} \\
Q=\sqrt{-\bar{P} \underline{P}}
\end{gathered}
$$

Since $\bar{P}$ and $\underline{\mathrm{P}}$ are of opposite sign, $\mathrm{Q}$ is a real number. 


\section{APPENDIX B}

\section{FLAT TOP OPERATION}

Power swing and flicker have been measured for the "User-3" cycle. This cycle includes an interval of flat-top or constant magnetic field operation. Flat-top operation of a magnet requires a substantial reduction in the voltage of the power supplies. If the reduced supply voltage is achieved by phase back of the SCR diodes then large values of reactive power will flow and induce amplitude flicker. This procedure was employed during the recent run of the Booster. The voltage can also be reduced by employing transformers with adjustable voltage taps and reducing the $\mathrm{AC}$ voltage at the rectifiers. This will avoid inducing excessive flicker. Since a slow extracted beam (SEB) mode is being studied, flicker and power measurements for the "User-3" cycle are of interest.

The dual trace oscillograms of Figure B-1 give the power supply voltage and the instantaneous power of one of the three phases. Unfortunately, a three-phase power measurement was not obtained. However, from the oscillogram of Figure B-1 and the procedure outlined in Appendix A, the real and reactive powers can be estimated. The oscillogram of Figure 4 also gives the real power.

Estimates of peak power for "User-3" are given in Table B-1.

\begin{tabular}{||c|c|c|c||}
\hline \multirow{2}{*}{ MODE } & DC BUS & \multicolumn{2}{|c|}{ AC BUS } \\
\cline { 2 - 4 } & REAL POWER & REAL POWER & REACTIVE POWER \\
\hline Rectify & $6.68 \mathrm{MW}$ & $7.2 \mathrm{MW}$ & 1.80 MVAR \\
\hline Flat Top & $.92 \mathrm{MW}$ & $1.35 \mathrm{MW}$ & 9.54 MVAR \\
\hline Invert & $6.36 \mathrm{MW}$ & $5.85 \mathrm{MW}$ & 3.24 MVAR \\
\hline
\end{tabular}

TABLE B-1

\section{POWER FOR "USER-3" CYCLE}

A summary of the measured and calculated values of flicker is given in Table B-2. 


\begin{tabular}{|c|c|c|c|c|}
\cline { 3 - 5 } \multicolumn{2}{c|}{} & BOOSTER $13.8 \mathrm{KV}$ FEED & LAB SITE & REDUCTION RATIO \\
\hline \hline \multirow{2}{*}{$\begin{array}{c}\text { PHASE } \\
\text { FLICKER }\end{array}$} & Measured & $2.17^{\circ}$ & $.24^{\circ}$ & 9.04 \\
\cline { 2 - 5 } & Calculated & $2.07^{\circ}$ & $.22^{\circ}$ & 9.41 \\
\hline $\begin{array}{c}\text { AMPLITUDE } \\
\text { FLICKER }\end{array}$ & Measured & $4.31 \%$ & $.42 \%$ & 10.26 \\
\cline { 2 - 5 } & Calculated & $3.42 \%$ & $.37 \%$ & 9.24 \\
\hline
\end{tabular}

TABLE B-2

\section{SUMMARY OF FLICKER VALUES FOR "USER-3" CYCLE}

Note the large value of amplitude flicker measured on site (.42\%) for a power swing of $13 \mathrm{MW}$. By employing adjustable voltage taps for flat-top operation, the amplitude flicker should be substantially reduced; the phase flicker values can be expected to be essentially the same.

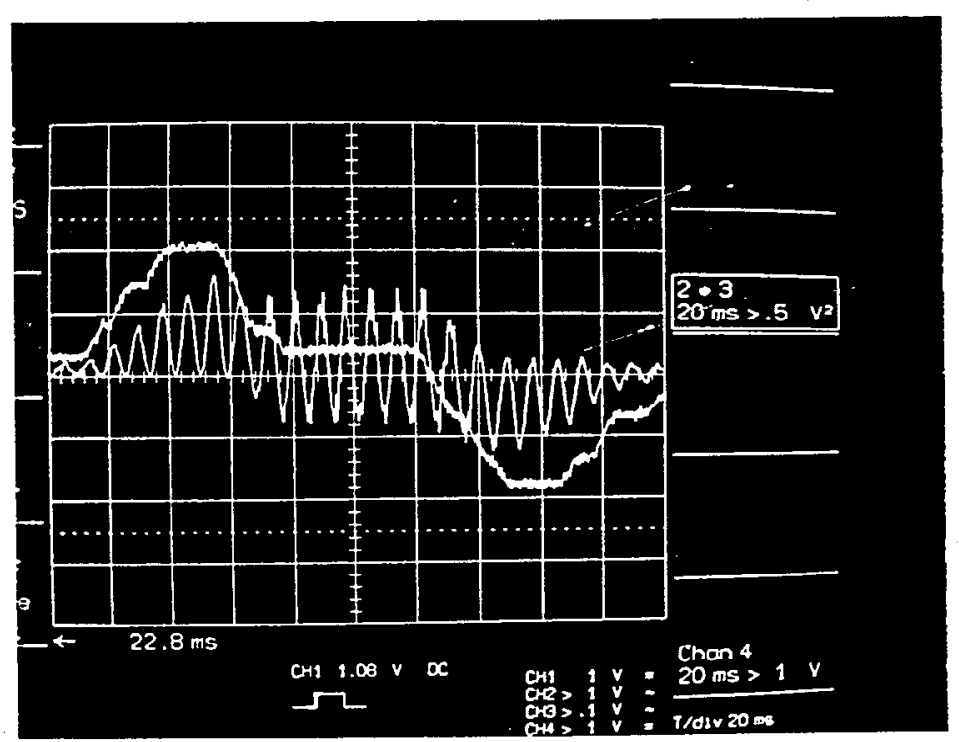

Figure B-1

Oscillogram of Magnet Voltage \& Instantaneous Power of One Phase

For Power Naveform:

$\begin{array}{ll}\text { Max. } & 1.04 \text { volt }^{2} \\ \text { Min. } & -.90 \text { volt }^{2} \\ \text { Scale } & 4.608 \mathrm{MW} / \text { volt }^{2}\end{array}$

